\title{
Acalculous cholecystitis presenting in an out-patient with no risk factors
}

\author{
M Goodier, MB ChB \\ S Mulira, MB ChB \\ S Andronikou, MB BCh, FCRad, FRCR (Lond), PhD \\ Department of Radiology, University of the Witwatersrand, Johannesburg
}

Corresponding author: M Goodier (goodiermatt@gmail.com)

\begin{abstract}
Acute acalculous cholecystitis (AAC) is recognised to occur in patients with serious co-morbid illnesses such as after major surgery, severe trauma, burns, multi-organ failure, systemic sepsis and prolonged intravenous hyperalimentation. The development of AAC in outpatients with none of the traditional risk factors appears to be increasing. The incidence of this form of AAC in South Africa has not yet been established. Prompt recognition of this condition and appropriate surgical management is necessary to minimise morbidity and mortality. This report describes a 52-year-old man who developed AAC in the absence of the usual risk factors.
\end{abstract}

\section{Background}

Acute acalculous cholecystitis (AAC) is acute inflammation of the gallbladder in the absence of gallstones. The condition has previously been regarded as occurring in the context of the intensive care unit in patients who are post major surgery or who have major systemic illnesses. According to international reports, the incidence of AAC developing in outpatients with none of the traditional risk factors appears to be increasing. ${ }^{1}$ To date, there have been no reports from South Africa regarding the local incidence of this form of AAC.

\section{Case report}

We present the case of a 52-year-old man presenting from home with right upper quadrant pain. He had a history of hypertension and was on hydrochlorothiazide $12.5 \mathrm{mg}$ daily. He was otherwise well with no history of diabetes mellitus, auto-immune disease or any other significant illness.

On examination, the patient was pyrexial and tachycardic. There was tenderness and peritonism localised to the right upper quadrant. There was laboratory evidence of a systemic inflammatory process, with a white cell count of $20.4 \times 10^{9}$ cells/l and a C-reactive protein (CRP) of $231.7 \mathrm{mg} / \mathrm{l}$. Electrolytes and liver enzymes were within normal limits. He tested HIVnegative.

Plain films of the abdomen were considered non-specific at the time. Ultrasound of the abdomen failed to demonstrate the gallbladder with prominent gas shadowing in the gallbladder fossa. The sonographic Murphy's sign was positive. A computed tomogram (CT) of the abdomen performed on admission showed a thickened gallbladder wall with surrounding inflammatory fatty stranding. The gallbladder lumen was noted to contain a significant amount of gas suggestive of a complicated cholecystitis (Fig. 1).

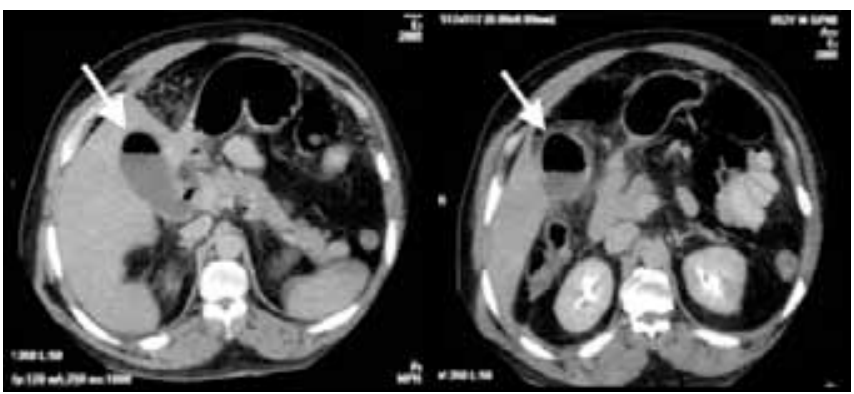

Fig. 1. Axial computed tomogram demonstrating the thick-walled gallbladder (arrow) which contains air. There is stranding in the surrounding mesenteric fat.

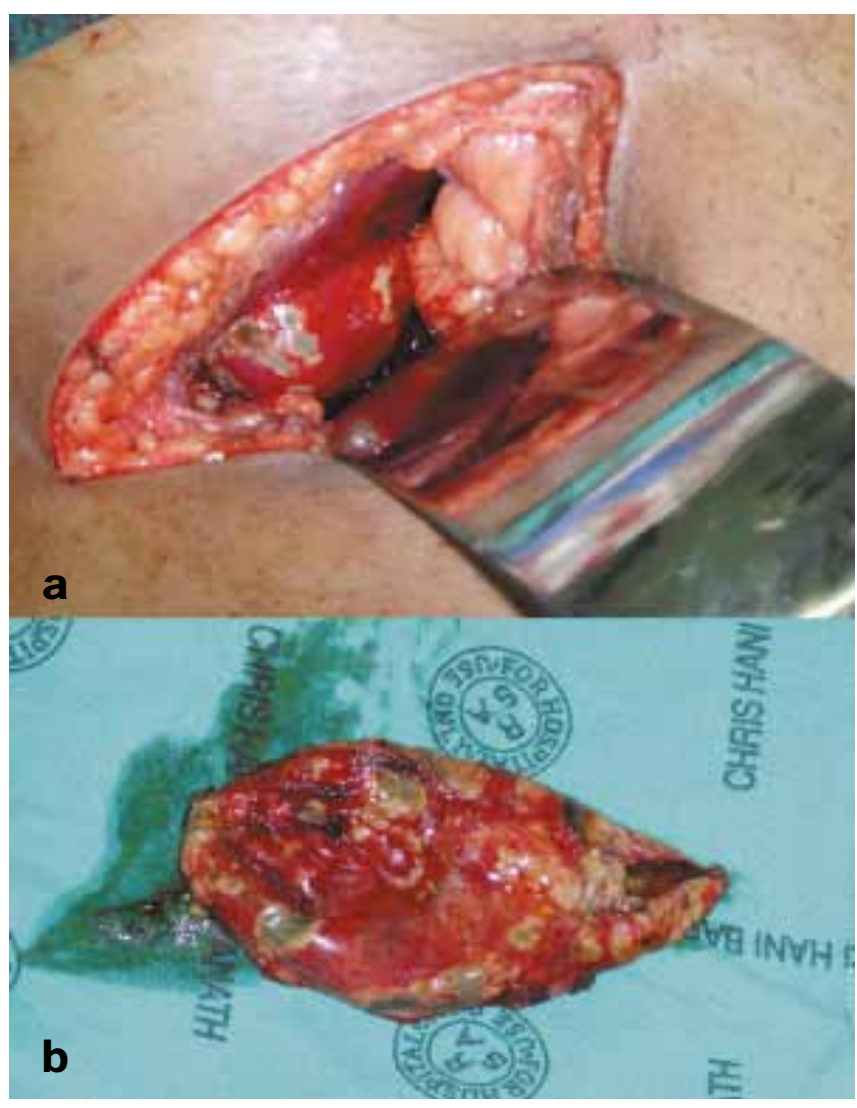

Fig. 2a. Intraoperative image demonstrating the inflamed gallbladder. Fig. 2b. Gross pathological specimen showing necrosis and gangrene of the gallbladder wall. No calculi were present within the gallbladder.

An open cholecystectomy was performed on day 2 post admission. The gallbladder appeared inflamed, gangrenous and necrotic (Fig. 2a). 
No gallbladder calculi were noted at operation. Pathological examination of the resected specimen showed features of an acute gangrenous cholecystitis (Fig. 2b).

Postoperative recovery was complicated with a repeat CT done on day 10 showing a small subhepatic collection that was treated conservatively. The patient was discharged on day 25 .

\section{Discussion}

Acalculous cholecystitis has traditionally been recognised to occur in patients with serious co-morbid illnesses especially after major surgery, severe trauma, burns, multi-organ failure, systemic sepsis and prolonged intravenous hyperalimentation. ${ }^{2}$ Diabetes and auto-immune conditions are also known risk factors. Patients with acquired immune deficiency syndrome (AIDS) may develop a cholecystitis secondary to opportunistic infection of the gallbladder. ${ }^{3}$ However, there have recently been an increasing number of reports in the literature of the occurrence of AAC in patients with none of the established risk factors. Two recent series suggest that, in some settings, a significant number of patients with acalculous cholecystitis present from home with no evidence of predisposing illness or trauma. This group of patients may comprise up to $14 \%$ of all outpatients with acute cholecystitis ${ }^{4}$ and as many as $77 \%$ of all patients finally diagnosed with AAC. ${ }^{5}$

The development of gallbladder inflammation in AAC is traditionally believed to be secondary to ischaemia. ${ }^{6}$ The cystic artery is an end artery with no significant source of collateral supply to the gallbladder. Ischaemia of the gallbladder in critically ill patients is often multifactorial, with dehydration, sepsis, gallbladder stasis with the accumulation of sludge and multiple transfusions being possible predisposing factors. The pathogenetic mechanisms of AAC in patients with no risk factors is as yet unclear; however, as many as $72 \%$ of these patients have evidence of atherosclerotic vascular disease. ${ }^{5}$ These patients are also commonly hypertensive (as was our patient), further suggesting that vascular disease may play a role in the pathogenesis of this condition. ${ }^{5}$

Acalculous cholecystitis had been considered to have a poor prognosis, but this most probably reflects the severity of the underlying condition. In patients with no major systemic illness, an increased incidence of gangrenous cholecystitis (as much as 59\%) has been reported, but this is possibly owing to diagnostic uncertainty and delay in performing surgery in this group of patients. ${ }^{4}$ With prompt and appropriate treatment, the outcome in the group of patents with no underlying systemic illness appears to be similar to patients with calculous cholecystitis. ${ }^{7}$

\section{Conclusion}

Although acalculous cholecystitis often occurs in the context of the intensive care unit in patients with major underlying illnesses, it should be recognised that a significant proportion of patients with this condition present as outpatients with no underlying risk factors. The incidence of this form of AAC in South Africa has not been established. Prompt recognition of this condition and surgical management is necessary to minimise the associated morbidity and mortality.

1. Parithivel VS, Gerst PH, Banerjee S, Parikh V, Albu E. Acute acalculous cholecystitis in young patients without predisposing factors. Am Surg 1999;65:366-368.

2. Kalliafas S, Ziegler DW, Flancbaum L, Choban PS. Acute acalculous cholecystitis: incidence, risk factors, diagnosis, and outcome. Am Surg 1998;64:471-475.

3. Yusuf TE, Baron TH. AIDS cholangiopathy. Curr Treat Options Gastroenterol 2004;7:111-117.

4. Ryu JK, Ryu KH, Kim KH. Clinical features of acute acalculous cholecystitis. J Clin Gastroenterol 2003;36:166-169.

5. Savoca PE, Longo WE, Zucker KA, McMillen MM, Modlin IM. The increasing prevalence of acalculous cholecystitis in outpatients. Results of a 7-year study. Ann Surg 1990;211:433-437.

6. Warren BL. Small vessel occlusion in acute acalculous cholecystitis. Surgery 1992;111:163-168.

7. Shridhar Ganpathi I, Diddapur RK, Eugene H, Karim M. Acute acalculous cholecystitis: challenging the myths. HPB 2007;9:131-134. 